\title{
Educação profissional tecnológica: uma revisão acerca da formação continuada de professores(as)
}

\author{
Technological professional education: a review on teachers' continuing education
}

Educación profesional tecnológica: una revisión sobre la formación continua del profesorado

\author{
Raiara Valau Keller ${ }^{\mathrm{I}}$, Eriques Piccolo Becker ${ }^{\mathrm{II}}$, Rosalvo Luis Sawitzki ${ }^{\mathrm{III}}$, Luis Eugênio Martiny ${ }^{\mathrm{IV}}$, Ana \\ Nathalia Almeida Callai ${ }^{\mathrm{V}}$
}

\begin{abstract}
Resumo
O presente estudo busca analisar a formação docente para atuação na Educação Profissional Tecnológica (EPT), além de discutir Formação Continuada (FC) de professores de Educação Física nessa modalidade de ensino. Para isso, foi realizado uma análise histórica da EPT, a Formação continuada e a implicação no trajeto formativo. Para o desenvolvimento deste estudo, foi utilizada uma pesquisa bibliográfica. Por fim, evidenciou-se a necessidade de se construir e/ou possibilitar espaços de FC para que os professores da EPT se instrumentalizem para enfrentar as peculiaridades referentes a esta modalidade de ensino e, assim, poder pensar sua prática pedagógica.
\end{abstract}

Palavras chaves: Docente; Educação profissional tecnológica; Formação Continuada

\begin{abstract}
The present study seeks to analyze teacher's education for acting in the Technological Professional Education (TPE), besides it discusses the importance of Continuing Education (CE) of Physical Education Teachers in this modality of teaching. For this, a historical analysis of the TPE was performed, the importance that the CE has and what it implies in the formative path. For the development of this study, a bibliographic research was used. Finally, it was clear the importance of building and / or enabling CE spaces for TPE teachers to instrumentalize to face the peculiarities of this teaching modality and, thus, be able to think about their pedagogical practice.
\end{abstract}

Keywords: Teachers; Technological Professional Education; Continuing Education

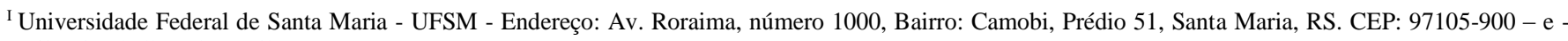
mail: raiarakeller@hotmail.com

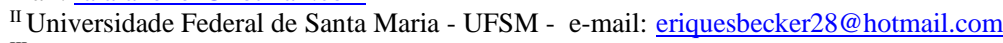

III Universidade Federal de Santa Maria - UFSM - e-mail: rosalvols@ hotmail.com

IV Instituto Federal de Educação, Ciência e Tecnologia do Rio Grande do Norte, IFRN, Brasil. e-mail: 1uis martiny@hotmail.com

v Universidade Federal de Santa Maria - UFSM - e-mail: ana.nathalia@ hotmail.com
} 


\section{Resumen}

El presente estudio busca analizar la formación docente para actuar en la Educación Tecnológica Profesional (EPT), además de discutir la importancia de la Educación Continua (EC) de los maestros de Educación Física en esta modalidad de enseñanza. Para esto, se realizó un análisis histórico de la EPT, la importancia que tiene la EC y lo que implica en el camino formativo. Para el desarrollo de este estudio, se utilizó una investigación bibliográfica. Finalmente, quedó claro la importancia de construir y / o habilitar espacios de EC para que los docentes de EPT puedan instrumentalizarse para enfrentar las peculiaridades de esta modalidad de enseñanza y, por lo tanto, puedan pensar en su práctica pedagógica.

Palabras clave: Docente; Educación profesional tecnológica; Formación Continua

\section{Introdução}

A Formação Continuada (FC) é uma possibilidade de qualificação para os professores, pois através dela pode-se discutir, em diversos espaços, como em reuniões pedagógicas e conselhos de classe, situações que ocorrem no dia-a-dia dos docentes, buscando capacitar os professores que estão na escola para uma educação que está em constante processo de mudança.

A formação docente, por si só, já é uma temática complexa, por abranger diversos campos de estudo e também por estar relacionada a todas as etapas da carreira docente, desde a Formação Inicial até a FC. Sendo essa última, responsável por dar continuidade a formação dos professores.

A FC é fato importante na construção da identidade docente, e mais que isso, serve como suporte de atuação pedagógica, uma vez que é sabido que a FI é apenas um primeiro passo em busca de uma qualidade profissional, e nesse sentido, de considerar a FC como suporte pedagógico que entende-se a importância de relacionar essa temática com a EPT.

Como veremos a seguir, a modalidade de ensino da EPT não é amplamente discutida e problematizada na graduação - formação inicial- e isso nos leva a uma enorme lacuna entre a teoria e a prática, o que consequentemente reflete na prática docente dos professores de Educação Física.

Discutir uma FC de qualidade para os professores que atuam na modalidade de ensino da EPT pode ser um caminho para o docente se sentir mais seguro e capacitado para desenvolver um ensino de qualidade no qual todos os alunos têm direito. Nesse enfoque, o presente artigo tem como tema a FC de professores do ensino técnico profissionalizante.

Outrossim, é de grande valia registrar que a EPT caracteriza-se por ser um nível de ensino existente a mais de 100 anos. É uma das modalidades de ensino em que os professores necessitam, também, de uma FC de qualidade e específica pensando em suas características. Porém, quando une-se FC e EPT, poucas discussões são encontradas. 
A presente investigação tem como objetivo geral analisar a EPT e como está articulada a FC de professores dentro dessa modalidade de ensino. Além disso, visa-se fazer um breve panorama histórico da EPT no Brasil e no Estado do Rio Grande do Sul (RS), percebendo as suas peculiaridades, além de identificar os diferentes modelos de FC disponível aos seus docentes e, por fim, (re)conhecer a importância da FC de professores de Educação Física na referida modalidade.

\section{Metodologia}

O trabalho possui caráter qualitativo, buscando evidenciar os fatores que são atribuídos a um determinado fenômeno (NEVES, 1996). Além disso, classificamos esta pesquisa como bibliográfica, uma vez que nos valemos de bibliografias já existentes para melhor embasar a discussão. Com isso, realizou-se uma busca maximizada, de caráter aleatório, com a intenção de ampliar a coleta dos trabalhos publicizados.

Após este primeiro momento, passou-se a analisar as discussões que estão sendo realizadas nos últimos anos sobre FC e sua relação com a EPT. Com isso, tem-se os resultados do estudo, que foram problematizados a partir da busca teórica e da discussão com autores.

\subsection{Um breve panorama histórico do ensino técnico profissional no Brasil}

A formação profissional remete a períodos remotos da história brasileira, inclusive foi direcionada inicialmente aos indígenas e aos escravos africanos. Entretanto, oficialmente, a Rede Federal de Educação Profissional e Tecnológica existe há mais de 100 anos no Brasil, tendo o ensino técnico iniciado em 1906, com o então Presidente Nilo Peçanha:

[...] por meio do Decreto $\mathrm{n}^{\circ} 787$, de 11 de setembro de 1906, criando quatro escolas profissionais naquela unidade federativa: Campos, Petrópolis, Niterói, e Paraíba do Sul, sendo as três primeiras, para o ensino de ofícios e a última à aprendizagem agrícola. (BRASIL, 2009, p02)

Apesar de ao longo dos anos, terem sido criadas mais Escolas de Aprendizes Artífices, todas essas destinadas ao ensino profissional, a temática somente passou a constar na legislação máxima do Brasil com a outorgação da Constituição Brasileira de 1937, que foi a primeira a tratar do assunto, a qual, em seu artigo 129 referiu:

O ensino pré-vocacional e profissional destinado às classes menos favorecidas é, em matéria de educação, o primeiro dever do Estado. Cumpre-lhe dar execução a esse dever, fundando institutos 
de ensino profissional e subsidiando os de iniciativa dos Estados, dos Municípios e dos indivíduos ou associações particulares e profissionais. É dever das indústrias e dos sindicatos econômicos criar, na esfera de sua especialidade, escolas de aprendizes, destinadas aos filhos de seus operários ou de seus associados. A lei regulará o cumprimento desse dever e os poderes que caberão ao Estado sobre essas escolas, bem como os auxílios, facilidades e subsídios a lhes serem concedidos pelo poder público.

Nesse mesmo ano, transformaram-se as Escolas de Aprendizes e Artífices em Liceus Profissionais, sendo que em 1942 passaram a se chamar de Escolas Industriais e Técnicas. Em 1959, passam a ser consideradas Escolas Técnicas Federais, ganhando alguma autonomia, especialmente didática e de gestão, na medida em que "intensificam a formação de técnicos, mão de obra indispensável diante da aceleração do processo de industrialização." (MEC, 2009, p.04).

Em decorrência, com o passar dos anos, novos documentos passaram a ser expedidos pelo governo federal versando acerca da ETP, por exemplo em 1967, através do Decreto 60.731/1967, as Escolas Técnicas Federais passam a serem nomeadas Escolas Agrotécnicas Federais (EAFs). Na década de 1990, mais especificamente em 1994, as escolas técnicas federais, transformam-se em Centros Federais de Educação Tecnológica.

Em 2008, a partir da Lei 11.892, de 29 de Dezembro de 2008, houve a criação da Rede Federal de Ensino (RFE) e dos Institutos Federais de Educação, Ciência e Tecnologia, abrangendo todos os Estados da Federação. A criação dessa lei, marcou um período considerável de expansão da rede profissional brasileira.

Conforme consta na página eletrônica da RFE, atualmente são 38 Institutos Federais (IFs) distribuídos em todos os estados brasileiros, com seus 644 campi em funcionamento. Ainda completam a RFE: dois Centros Federais de Educação Profissional e Tecnológica (Cefets), vinte e cinco escolas vinculadas a universidades, a Universidade Tecnológica e o Colégio Pedro II.

No estado do Rio Grande do Sul (RS) a EPT está representada por três institutos: O Instituto Federal Farroupilha (IFFar), o Instituto Federal do Rio Grande do sul (IFRS) e o Instituto Federal Sul Rio-Grandense (IFSul), os quais ofertam cursos técnicos, graduações e pós-graduações. Segue na tabela I os números dos cursos desses Institutos Federais: 
Tabela I- Panorama atual dos IF no Estado do RS

\begin{tabular}{lccc}
\hline \hline & $\begin{array}{c}\text { Instituto Federal } \\
\text { Farroupilha } \\
\text { (IFFar) }\end{array}$ & $\begin{array}{c}\text { Instituto Federal } \\
\text { do Rio Grande do } \\
\text { Sul (IFRS) }\end{array}$ & $\begin{array}{c}\text { Instituto Federal } \\
\text { Sul Rio-Grandense } \\
\text { (IFSul) }\end{array}$ \\
\hline \hline $\mathrm{N}^{\circ}$ de Campi & 11 & 17 & 14 \\
\hline $\mathrm{N}^{\circ}$ de Cursos Técnicos & 46 & 48 & 40 \\
\hline $\mathrm{N}^{\circ}$ de Cursos de Graduação & 23 & 37 & 19 \\
\hline $\mathrm{N}^{\circ}$ Cursos de pós-graduação & 10 & 17 & 13 \\
\hline \hline
\end{tabular}

Fonte: Site Institucional do Instituto Federal Farroupilha (2015)

Já no mapa a seguir, podemos perceber a abrangência geográfica dos IFs no Estado do Rio Grande do Sul:

Figura 1 - Distribuição dos IFs no Estado do Rio Grande do Sul

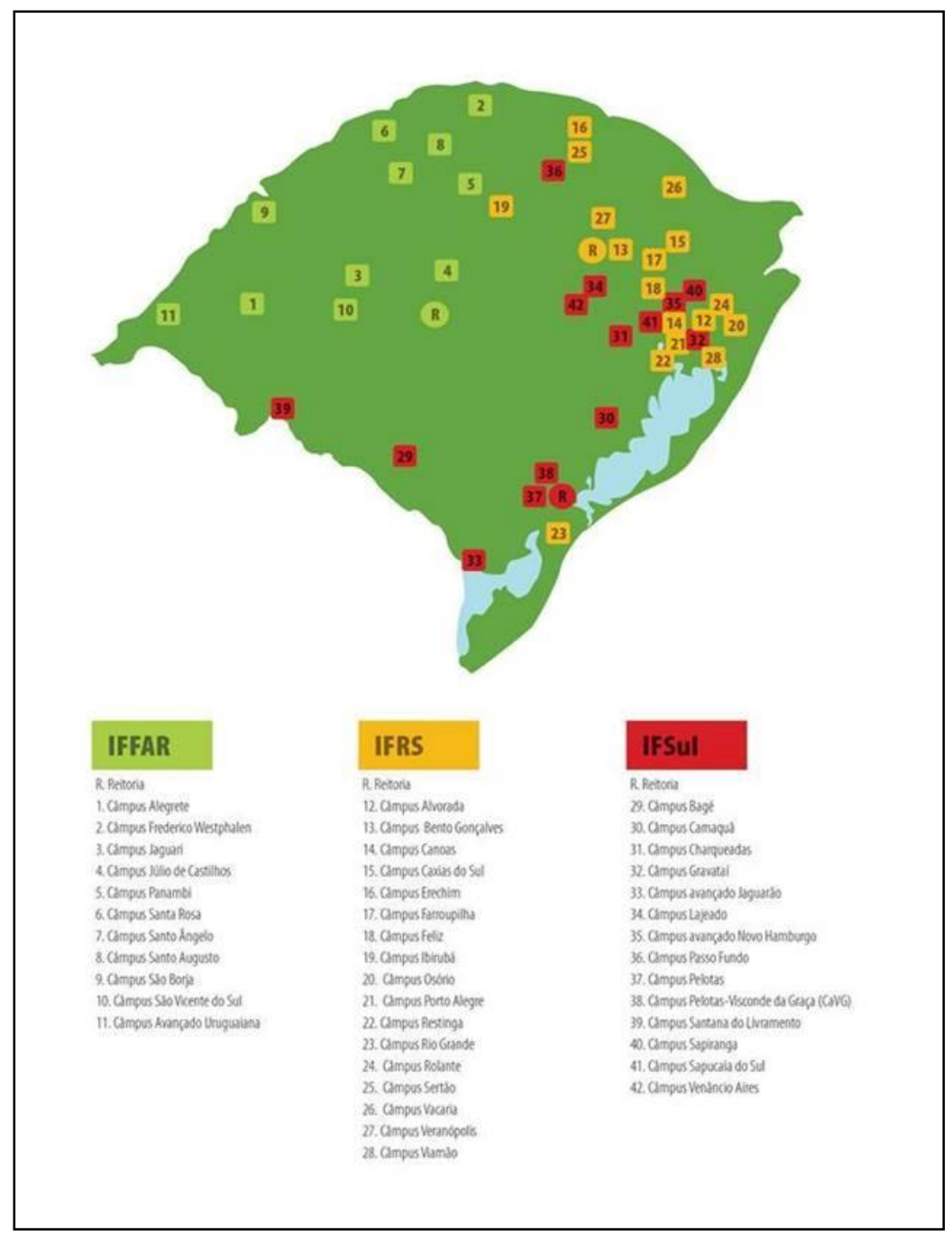

Fonte: Site Institucional do Instituto Federal Farroupilha (2015) 
A RFE mostra sua grande expansão, caracterizando-se como uma oportunidade para o ensino médio integrado, além de cursos de qualificação e cursos superiores de bacharelado, tecnologia e licenciaturas.

O ensino técnico profissionalizante é uma modalidade de ensino em plena ascensão, tanto no estado do RS, como no Brasil. Sua finalidade caracteriza-se em preparar o aluno para o mundo do trabalho, sem deixar de lado sua criticidade e autonomia. Tem suas peculiaridades, dificuldades e desafios. Porém, conforme salienta Pacheco (2011):

\begin{abstract}
Os Institutos Federais de Educação, Ciência e Tecnologia são a síntese daquilo que de melhor a Rede Federal construiu ao longo de sua história e das políticas de educação profissional e tecnológica do governo federal. São caracterizados pela ousadia e inovação necessárias a uma política e a um conceito que pretendem antecipar aqui e agora as bases de uma escola contemporânea do futuro e comprometida com uma sociedade radicalmente democrática e socialmente justa. (2011, p.08)
\end{abstract}

Assim, essa modalidade tem se destacado cada vez mais nos últimos anos, tornando-se uma possibilidade de caminho educacional para os alunos e também um campo de atuação para os professores.

\title{
2.2 Educação Básica e Educação Profissional e Tecnológica (EPT)
}

Quando se fala no contexto educacional em que vivemos, muitas questões acabam sendo levantadas, seja a partir de políticas públicas educacionais, ou pelo contexto sócio-político, pois esses dois tópicos influenciam na área educacional diretamente. A partir da premissa de que a EPT tem algumas peculiaridades que a diferencia da educação básica, buscar-se-á discutir acerca dessas questões a partir de apontamentos de ordem legal e pedagógico, os quais contribuirão para essa reflexão.

Primeiramente, considerando os aspectos legais, a Lei de Diretrizes e Bases da Educação de 1971 (Lei 5.692) traz como aspecto importante a inclusão técnico-profissional no $2^{\circ}$ grau:

\footnotetext{
Art. $1^{\circ} \mathrm{O}$ ensino de $1^{\circ}$ e $2^{\circ}$ graus tem por objetivo geral proporcionar ao educando a formação necessária ao desenvolvimento de suas potencialidades como elemento de auto-realização, qualificação para o trabalho e preparo para o exercício consciente da cidadania. (grifo nosso).
}

Trata-se, pois, do primeiro indicativo da educação profissional no ensino médio, sendo que, posteriormente, com a Lei de Diretrizes e Bases da Educação Nacional de 1996 (Lei 9.394/96) esta, trouxe em seus domínios um regulamento especifico para a EPT na Seção IV - A: Da Educação 
Profissional e Tecnológica, fato que demonstra que esta possui diferenciações em relação à Educação Básica.

Outro aspecto que reflete essa diferenciação entre Educação Básica e a EPT é a forma de ingresso nas Instituições de Ensino. Na Educação Básica, em geral, não há nenhum tipo de seleção específica, cabendo apenas a inscrição do aluno na escola que deseja estudar. Contudo, na EPT, o aluno que se interessar, deve submeter-se ao processo seletivo, concorrendo a vaga, de acordo com as disposições previstas em edital, regulamentado conforme cada instituição de EPT. Normalmente são aplicadas provas contendo questões de várias áreas do conhecimento, de caráter classificatório para serem preenchidas a quantidade de vagas pré-determinadas.

Ainda, as modalidades de ensino são um ponto a ser analisado, uma vez que conforme consta na LDB 9394/96 (1996), o ensino técnico de nível médio pode ser desenvolvido das seguintes formas: I articulada com o ensino médio (integrada e concomitante) e II - subsequente, sendo que na educação básica há apenas o ensino regular. A forma integrada, segundo a legislação, é definida como:

Ofertada somente a quem já tenha concluído o Ensino Fundamental, com matrícula única na mesma instituição, de modo a conduzir o estudante à habilitação profissional técnica de nível médio ao mesmo tempo em que conclui a última etapa da educação básica. (LDB, 2015, p.26)

Entretanto, na forma concomitante, a LDB 9394/96 denomina como sendo aquela "Oferecida a quem ingresse no ensino médio ou já o esteja cursando, efetuando-se matrículas distintas para cada curso" (LDB, 1996, p.26). Nessa forma, o ensino pode acontecer na mesma ou em instituições distintas através de convênios.

A modalidade subsequente é quando o aluno já está com o ensino médio concluído e cursa somente o ensino técnico na instituição. Nesse sentido, percebe-se que a EPT abrange um ensino mais diversificado do que somente a Educação Básica de nível médio, abrangendo também Ensino Integrado, Concomitante e Subsequente. Pode-se dizer que essa variedade de cursos e áreas diferentes potencializa a EPT, fato este reforçado por Pacheco (2011, p.15) ao afirmar que: Com os Institutos Federais iniciamos uma nova fase, abandonando o hábito de reproduzir modelos externos e ousando inovar a partir de nossas próprias características, experiências e necessidades.

Considerando seus objetivos, no Art. 35 da LDB 9393/96 (1996) há referência de que o ensino médio foca na "consolidação e aprofundamento dos conhecimentos adquiridos no ensino fundamental, possibilitando o prosseguimento dos estudos”. Já o objetivo principal da EPT, previsto no Art. 36-A, 
refere-se à preparação para o mundo do trabalho, indo além da formação básica. Reforçando esse ponto, cita-se Pacheco (2011) o qual refere que:

\begin{abstract}
Nosso objetivo central não é formar um profissional para o mercado, mas sim um cidadão para o mundo do trabalho - um cidadão que tanto poderia ser um técnico quanto um filósofo, um escritor ou tudo isso. Significa superar o preconceito de classe de que um trabalhador não pode ser um intelectual, um artista. (PACHECO, 2011, p.11).
\end{abstract}

Assim, por esses motivos que a EPT é uma modalidade de ensino diferenciada das demais e, por essa razão, pensar a atuação do professor é essencial, uma vez que este deverá conhecer essas peculiaridades e se preparar para enfrentá-las de modo a desenvolver suas aulas da melhor maneira possível, visando uma educação contextualizada com a realidade dos alunos, trazendo aspectos relevantes do futuro campo de atuação dos mesmos.

\title{
2.3 A Formação Continuada
}

De acordo com o dicionário Aurélio (2010), "Formação" significa: constituição, ato ou efeito de formar ou formar-se. Nesse sentido, partindo da ideia de que a formação e/ou constituição de cada ser é feita a partir daquilo que se vivencia diariamente ou ao longo de sua vida, é que a profissão docente também é assim constituída, por uma construção de saberes e conhecimentos adquiridos pelas experiências e vivências (TARDIF, 2008). Dessa forma, Rossi (2012), entende FC como sendo:

Dimensão da formação constitui-se num processo contínuo e ininterrupto, que percorre toda a trajetória profissional do professor, sempre com o intuito de aprimorar a sua ação pedagógica e desenvolver a sua profissionalidade docente, a sua identidade. (ROSSI, 2012, p.323).

Esse tipo de formação poderá servir como auxílio, pois cada vez mais precisa-se qualificar os docentes de forma que possam enfrentar seus problemas e encontrar diferentes alternativas pedagógicas para solucioná-los. Assim como confirma Mediano (1997) e Günther e Molina Neto (2000):

Ao longo das últimas décadas, a formação continuada de professores vem ocupando lugar significativo nos debates educacionais contemporâneos, revelando-se como uma preocupação por parte do poder público, entre as universidades e centros de pesquisa (1997) e entre os docentes que estão atuando na escola (GÜNTHER; MOLINA NETO, 2000, p.324). 
Os desafios para esses docentes estão cada vez maiores, pois vivemos em tempos de constantes questionamentos ao professorado, bem como se perpetua uma desvalorização docente, isso sem contar as condições de trabalho precárias, o que dificulta o acesso a FC necessária para suprir as demandas que emergem no cotidiano escolar.

A constatação acima referida se reflete na prática da escola, onde os professores somente participam da formação que a escola oferece, quando oferece. Por vezes essa oferta de capacitação/formação é descontextualizada com a realidade, e/ou são atividades pouco atrativas, havendo a participação docente somente por obrigação. Conforme constatam Becker, Keller e Sawitzki (2016):

O que acontece é que, muitas vezes, a equipe diretiva das escolas fornece ou oferece aos professores modelos de formação continuada que não atendem as necessidades dos docentes, uma vez que o que impulsiona os professores a procurarem uma atualização da profissão são as respostas para os problemas que surgem durante a prática pedagógica. (BECKER; KELLER; SAWITZKI, 2016, p.38).

Sendo assim, os professores necessitam buscar motivação e achar tempo entre a rotina escolar, que envolve provas, trabalhos, aulas e vida pessoal para procurar alternativas específicas que estejam totalmente interligadas entre problema $\mathrm{x}$ alternativas $\mathrm{x}$ melhorias. Tudo isso pensando no aprender do aluno e em seu crescimento profissional, apesar da complexidade que permeia a resolução dessa equação na prática.

Para que isso ocorra, existem algumas possibilidades pela qual o professor da RFE pode-se valer a fim de conseguir dar andamento em seu processo de FC. Tanto de forma legal, com possibilidade de afastamento do cargo para capacitação, conforme consta na Lei 8.112/90 Art. 87:

\footnotetext{
Após cada qüinquiênio de efetivo exercício, o servidor poderá, no interesse da Administração, afastar-se do exercício do cargo efetivo, com a respectiva remuneração, por até três meses, para participar de curso de capacitação profissional.
}

Vale destacar, que vários são os espaços formativos que oferecem aos professores momentos de reflexão de sua prática, muitos deles ocorrem na escola, como reuniões pedagógicas, palestras e oficinas. Portanto, existem algumas possibilidades de FC previstas em lei e algumas também ofertadas pelas escolas, todas elas com a intenção de dar suporte e qualidade no desenvolver de suas aulas. 


\subsection{Formação Continuada e o Ensino Técnico Profissional}

Considerando que o Ensino Técnico Profissional atinge uma gama de modalidades de ensino, eixos tecnológicos e características peculiares, sendo a principal delas preparar seus alunos para o mundo de trabalho, a FC dos professores necessita considerar todos esses aspectos e assim auxiliá-los em sua atuação. Muitas são as atribuições do professor do Ensino Técnico Profissional, como a integração entre os conhecimentos científicos, tecnológicos, sociais e humanísticos. De acordo com Machado (2008, p.17), “é preciso considerar a complexidade deste todo e as necessidades de cada uma das particularidades internas ao conjunto da educação profissional brasileira”.

Esse professor necessita estar preparado para vários tipos de aprendizes e modalidades de ensino, para poder contextualizar, integrar e trocar conhecimentos através de suas aulas. A FC poderá ser o caminho para que esse professor se sinta preparado para isso. Logicamente, a FC para a EPT é complexa, por englobar vários aspectos, como alguns referidos acima, porém totalmente necessária para uma educação técnica de qualidade.

Para isso, faz-se necessário um professor curioso e envolvido, que se preocupe com sua formação e prática pedagógica. Assim como destaca Machado (2008):

É pressuposto básico que o docente da educação profissional seja, essencialmente, um sujeito da reflexão e da pesquisa, aberto ao trabalho coletivo e à ação crítica e cooperativa, comprometido com sua atualização permanente na área de formação específica e pedagógica, que tem plena compreensão do mundo do trabalho e das redes de relações que envolvem as modalidades, níveis e instâncias educacionais, conhecimento da sua profissão, de suas técnicas, bases tecnológicas e valores do trabalho, bem como dos limites e possibilidades do trabalho docente que realiza e precisa realizar. (MACHADO, 2008, p.17).

Outro aspecto relevante refere-se a necessidade das instituições estarem envolvidas e perceberem qual é a real necessidade do professor, quais as suas dificuldades, medos e anseios para assim, através da FC, discutir e procurar soluções para possíveis problemas vivenciados no dia-a-dia, tendo como objetivo central a melhoria da educação e o sucesso dos alunos.

Alguns modelos de aprendizagem na FC são conhecidos e poderiam servir como auxílio para uma qualificação profissional. São alguns deles conforme classifica Garcia (2002):

(a) "aprender de outros", como nos cursos, que se concretiza com a aplicação de conteúdos elaborados por especialistas no campo do conhecimento disciplinar. Embora os cursos sejam feitos em reuniões grupais, a aprendizagem é sempre individual; (b) "aprender com os outros", baseado no princípio de aprendizagem grupal, com perfil colaborativo. Esse tipo de aprendizagem 
nem sempre é presencial, pois o processo firma-se na realização de metas e de objetivos de aprendizagem comuns a um determinado grupo; (c) "aprender sozinho", como a autoformação, em que é fundamental o aprendizado mediante processos abertos que possibilitam ao profissional determinar suas próprias metas e valorizam a experiência como fator essencial para o desenvolvimento da reflexão e aprendizagem; e (d) "aprendizagem informal", que ocorre pela busca ocasional de informações e de experiências entre pares. É considerado um modelo que gera processos de aprendizagem importantes para o desenvolvimento profissional. (GARCIA, 2002, p.170).

Não faltam opções para FC, já que os professores podem se valer de cursos, palestras, oficinas, seminários e também pós-graduação. As oficinas e seminários seguem um caráter mais clássico, em que normalmente existe uma pessoa responsável por encaminhar determinados assuntos e discussões, outro exemplo de espaço de FC que junta-se com essa categoria são os cursos e palestras. Há possibilidades também de formações que seguem um caminho mais critico e inovador, como, por exemplo, a autoformação e as formações colaborativas.

Então, permanecer em constante atualização e buscando inovações poderá ser o caminho no qual o docente pode se valer para desenvolver de forma satisfatória suas aulas na EPT. Como nos lembra Bachelard (1997, p.79) "continuar sendo estudante deve ser o voto secreto de todo professor."

\subsection{Papel do professor de Educação Física}

Considerando os aspectos discutidos ao longo do texto, sobretudo pensando sobre FC e EPT, a pergunta que vem em mente é: qual o papel do professor de Educação Física neste contexto?

Presente geralmente na modalidade integrada, por ser uma disciplina da base comum, a Educação Física é ministrada pelo professor que, ao ingressar na EPT possui sua carreira vinculada à EBTT, ou seja, Educação Básica, Técnica e Tecnológica, fato que confere ao profissional a prerrogativa de atuar em qualquer nível de ensino - ensino médio integrado, ensino médio subsequente e curso superior de graduação - abrindo o leque de atuação, além da disciplina específica de Educação Física.

Durante a Formação Inicial do licenciado em Educação Física poderá existir uma lacuna referente a EPT, pois pouco é tratado de modalidades de ensino com peculiaridades que as diferenciam do ensino dito regular, ou da chamada Educação Básica.

Por esse motivo a FC do professor de Educação Física é tão importante, já que após ele estar inserido nesse contexto e sabendo das principais dificuldades que ele encontrará, poderá se capacitar e 
assim conseguir construir sua prática pedagógica pensando na modalidade de ensino na qual está desenvolvendo suas aulas.

Independente do contexto no qual o professor está inserido, salientamos que o professor de Educação Física, em nenhuma realidade ou modalidade de ensino, deverá abrir mão de sua FC, uma vez que é através dela que terá possibilidades de melhorar sua prática pedagógica e construir aulas sistematizadas e de qualidade.

Com isso, vale destacar as contribuições que essa melhoria em sua ação docente possa vir a oferecer aos alunos, que na verdade, são os protagonistas do processo de ensino e de aprendizagem. Deixamos claro aqui a importância da Educação Física enquanto disciplina em qualquer modalidade escolar, uma vez que segundo Darido (2005), ela tem um papel importante na cidadania de seus alunos, buscando através de práticas corporais adentrar no campo social dos mesmos.

Um estudo realizado por Kogut, Da Silva e Ribeiro (2015), mostra que a Educação Física ainda está ligada as questões esportivas, o que segundo eles, na visão dos alunos, a torna uma disciplina repetitiva e desmotivadora, tendo sua importância reduzida em grande parte. Mais um motivo para buscar uma FC, no intuito de superar essa visão fragmentada da Educação Física.

Muito além dos benefícios físicos relacionados à saúde, e bem estar (BARROS, 1993) (CAROL; DWYER, 1991), a Educação Física exerce um papel social, assim como a Educação em geral. Ser professor de Educação Física está diretamente ligado ao ser social, ao ser pedagógico, ao ser corporal, ou seja, a disciplina Educação Física, sendo ela na Educação Básica ou na EPT, deve considerar todos esses aspectos acima citados, e cabe não só ao professor fazer isso, mas também é um de seus papéis enquanto formador.

Esse professor tem como uma das alternativas integrar-se com os demais colegas professores e participar de todas as possibilidades de FC, como reuniões pedagógicas e conselhos de classe, para assim se sentir parte integrante do conjunto de professores e valorizar sua área de atuação. Também é importante manter-se interessado e atuante nas instituições. Como destaca Rossi e Hunger (2012):

Ao tratar da profissão docente na atualidade enfatiza-se, em praticamente todos os contextos escolares, a questão da formação continuada de professores, sendo concebida como uma tarefa coletiva entre professores, gestores, pesquisadores e outros atores do campo educacional. Essa dimensão da formação constitui-se num processo contínuo e ininterrupto, que percorre toda a trajetória profissional do professor, sempre com o intuito de aprimorar a sua ação pedagógica e desenvolver a sua profissionalidade docente, a sua identidade. (ROSSI; HUNGER, 2012, p.323). 
Assim, o professor de Educação Física, como qualquer outro, necessita sempre buscar o melhor para suas aulas, independente da modalidade de ensino que estiver inserido.

\section{Considerações finais}

Ao decorrer da analise da EPT, percebe-se que essa modalidade de ensino é bem peculiar, sendo que o professor que está inserido deverá se preparar para enfrentar essa demanda. Para tanto, a FC é uma das possibilidades, tanto a oferecida pela instituição, como todas as possibilidades na qual o professor se mostrar interessado. A legislação evidencia garantir ao professor esse direito.

Este estudo aponta que há uma necessidade de se pensar cada vez mais em oportunidades de formação continuada para os professores da modalidade de ensino profissionalizante técnico. Haja vista que através desses momentos de FC, norteados por politicas públicas, o professor conseguira adquirir capacidade de atuar em vários níveis de ensino e aprimorar suas práticas pedagógicas para assim capacitar seu aluno com excelência para o mundo do trabalho.

Outrossim, valorizar a carreira docente e manter-se em estado de atualização deve ser o objetivo de todo professor, instituições e demais órgãos públicos, razão pela qual esses atores devem preservar a disposição para o oferecimento de oportunidades para os docentes obterem e instigá-los a participarem da formação continuada de qualidade.

Além disso, em se tratando de uma FC voltada a professores de Educação Física atuantes na EPT, pode-se dizer que o caminho a ser percorrido ainda é grande, e hoje, não é possível dizer que existem muitos espaços formativos que auxiliem os professores Educação Física na atuação nessa modalidade. Se a FI em Educação Física não problematiza e não aproxima os professores dessa realidade, a FC,

infelizmente não se diferencia nesse aspecto. É preciso discutir e refletir mais sobre EPT e Educação Física, e debater sobre espaços formativos destinados a esse segmento profissional.

Enfim, poucas são as discussões englobando FC e EPT e é com flexões acerca desses assuntos que poderá se aprimorar a formação continuada nessa modalidade e por conseguinte, cada vez mais uma educação de qualidade e capaz de atingir o objetivo de transformar o aluno em cidadão crítico, reflexivo e habilitado para o mundo do trabalho especializado. 


\section{Referências}

BACHELARD, Gaston. O racionalismo aplicado. Rio de Janeiro: Zahar, 1977.

BECKER, E. P.; KELLER, R. V; SAWITZKI R. As Contribuições e Implicações do PIBID na Formação Continuada em Serviço de Professores (as) Supervisores (as). Kinesis, Santa Maria - RS, v.35, n.2, p.36-42, maio/ago. 2017. Disponível em < https://periodicos.ufsm.br/kinesis/article/view/26514

$>$ Acesso em: 30 de outubro de 2017.

BARROS R. Os adolescentes e o tempo livre: lazer - atividade física. In: Coates V, Françoso LA, Beznos GW. Medicina do adolescente. São Paulo: Sarvier, 1993

BRASIL, Fixa Diretrizes e Bases para o ensino de $1^{\circ}$ e $2^{\circ}$ graus, e dá outras previdências. Lei $\mathrm{N}^{\circ}$ 5.692, de 11 de Agosto de 1971. Disponível em: < http://www.planalto.gov.br/ccivil_03/leis/L5692.htm> Acesso em: 12 de Outubro de 2017.

BRASIL, LDB nacional [recurso eletrônico] : Lei de diretrizes e bases da educação nacional : Lei $\mathbf{n}^{\mathbf{0}}$ 9.394, de 20 de dezembro de 1996, que estabelece as diretrizes e bases da educação nacional. -11. ed. - Brasília : Câmara dos Deputados, Edições Câmara, 2015. - (Série legislação ; n. 159). ISBN 97885-402-0357-0

BRASIL, Lei no 8.112, de 11 de dezembro de 1990. Disponível em: <http://www.planalto.gov.br/ccivil_03/leis/L8112cons.htm> Acesso em: 15 de Outubro de 2017.

BRASIL, Ministério da educação. Cenário da rede federal de educação profissional e tecnológica. Brasilia, $2009 . \quad$ Disponível em: 〈http://portal.mec.gov.br/setec/arquivos/centenario/historico_educacao_profissional.pdf> Acesso em: 9 de Setembro de 2017.

BRASIL, Rede Federal de Educação Profissional, Cientifica e Tecnológica. Disponível em: < http://redefederal.mec.gov.br> Acesso em: 09 de Outubro de 2017.

CAROL N, DWYER JD. Nutrition and exercise: effects on adolescent health. Annu.

Rev. Publ. Health 1991; 12: 309-33

DARIDO, S. C; RANGEL, I. C. A. Educação física na escola: implicações para a prática pedagógica. Rio de Janeiro: Guanabara Koogan, 2005. 293 p

FERREIRA, A. B. de H. Dicionário da língua portuguesa. 5. ed. Curitiba: Positivo, 2010. 2222 p. ISBN 978-85-385-4198-1.

FERREIRA, J. S. ; HENRIQUE, J. ; COSTA, B. O. Perfil de formação continuada de professores de educação física: modelos, modalidades e contributos para a prática pedagógica. Revista Brasileira de Ciências do Esporte. v. 37, n. 3, p. 289-298, jul./set., 2015. Disponível em: < http://revista.cbce.org.br/index.php/RBCE/article/view/1709 > Acesso em: 24 de Outubro de 2017.

GARCIA, C. M. La formacion inicial y permanente de los educadores. In: Consejo Escolar del Estado. Los educadores en la sociedad del siglo XXI. Madrid: Ministerio de Educación, Cultura y Deporte, Universidad de Sevilla; 2002. p. 161---94. 
GÜNTHER, M.C.C.; MOLINA NETO, V. Formação permanente de professores de educação física na rede municipal de ensino de Porto Alegre: uma abordagem etnográfi ca. Revista Paulista de Educação Física, São Paulo, v.14, n.1, p.85-91, 2000.

KOGUT, M. C.; DA SILVA, J. W.; RIBEIRO, G de M. Contribuições do professor de educação física na formação cidadã do aluno no ensino médio. Anais do XIX Congrasso Brasileiro de Ciências do Esporte/CONBRACE. Vitória - $\quad$ ES. 2015. Disponível em: < http://congressos.cbce.org.br/index.php/conbrace2015/6conice/paper/viewFile/7506/3623> Acesso em: 16 de fevereiro de 2020.

MACHADO, L. R. S. Diferenciais inovadores na formação de professores para a educação profissional. Revista brasileira da educação profissional e tecnológica. Brasília. v1., n1., 8-22, junho, 2008.

MEDIANO, Z.D. A formação em serviço de professores através de ofi cinas pedagógicas. In: CANDAU, V.M. (Org.). Magistério: construção cotidiana. 4. ed. Petrópolis: Vozes, 1997. p.91-109

PACHECO, E. Institutos federais uma revolução na educação profissional e tecnológica. $1^{\circ}$ edição. Brasília: Ed. Moderna, 2011. ISBN 978-85-16-07375-6.

ROSSI, F.; HUNGER, D. As etapas da carreira docente e o processo de formação continuada de professores de Educação Física. Rev. bras. Educ. Fís. Esporte, São Paulo, v.26, n.2, p.323-38, abr./jun. 2012

TARDIF, M.. Saberes docentes e formação profissional. Petrópolis, RJ. Vozes, 2008.

\section{Como citar este artigo}

KELlER, R. V.; BECKER, E. P.; SAWITZKI, R. L.; MARTINY, L. E.; CALlAI, A. N. A. Educação profissional tecnológica: uma revisão acerca da formação continuada de professores(as). Revista Kinesis, Santa Maria, v.38, p.01-15 2020.

* O presente trabalho não contou com apoio financeiro de nenhuma natureza para sua realização. 